\title{
JBIR-124: a novel antioxidative agent from a marine sponge-derived fungus Penicillium citrinum Spl080624G1f01
}

\author{
Teppei Kawahara ${ }^{1}$, Motoki Takagi ${ }^{1}$ and Kazuo Shin-ya ${ }^{2}$
}

The Journal of Antibiotics (2012) 65, 45-47; doi:10.1038/ja.2011.98; published online 19 October 2011

Keywords: antioxidative agent; Penicillium; radical scavenging; sorbicillin; sorbicillinol

Active oxygen species cause many diseases such as atherosclerosis, inflammation, ischemia-reperfusion injury, rheumatoid arthritis and central nervous diseases. ${ }^{1}$ Furthermore, senility and cancer initiation and progression are also believed to involve active oxygen species. ${ }^{2}$ Thus, it is expected that effective antioxidative agents may prevent the onset and development of these diseases. In the course of our screening program for novel antioxidants, we have already reported the isolation of a new sorbicillinoid derivative, designated JBIR-59, ${ }^{3}$ from cultures of Penicillium citrinum SpI080624G1f01 isolated from marine sponges collected offshore of Ishigaki Island, Okinawa Prefecture, Japan. Further screening of the cultures resulted in the isolation of a new JBIR-59 derivative designated as JBIR-124 (1, Figure 1). This paper describes the isolation, structure elucidation and brief biological activity of $\mathbf{1}$.

SpI080624G1f01 was cultivated in 50-ml test tubes containing $15 \mathrm{ml}$ of potato dextrose broth $\left(24 \mathrm{gl}^{-1}\right.$ potato dextrose; BD Biosciences, San Jose, CA, USA). The test tubes were shaken on a reciprocal shaker (320 r.p.m.) at $27^{\circ} \mathrm{C}$ for 2 days. Aliquots $(5 \mathrm{ml})$ of the culture were transferred to $100-\mathrm{ml}$ Erlenmeyer flasks containing $3 \mathrm{~g}$ of brown rice (Hitomebore, Miyagi, Japan), $6 \mathrm{mg}$ of Bacto-yeast extract (BD Biosciences), $3 \mathrm{mg}$ of sodium tartarate, $3 \mathrm{mg}$ of potassium hydrogen phosphate and $9 \mathrm{ml}$ of water and were incubated in static culture at $27^{\circ} \mathrm{C}$ for 14 days.

The mycelia (gathered from 50 flasks) was extracted with $80 \%$ aqueous $\mathrm{Me}_{2} \mathrm{CO}(1400 \mathrm{ml})$ and filtered. After removal of $\mathrm{Me}_{2} \mathrm{CO}$ from the extract, the aqueous concentrate was extracted with EtOAc (1 liter $\times 3$ ). The obtained organic layer was dried over anhydrous $\mathrm{Na}_{2} \mathrm{SO}_{4}$ and evaporated to dryness. The dried residue $(4.9 \mathrm{~g})$ was subjected to normal-phase medium-pressure liquid chromatography (Purif-Pack SI-30, Shoko Scientific Co., Yokohama, Japan) and eluted with a gradient system of $n$-hexane-EtOAc (0-25\% EtOAc) followed by the stepwise solvent system of $\mathrm{CHCl}_{3}-\mathrm{MeOH}(0,2,5,10,20,30$ and $100 \% \mathrm{MeOH})$. The $5 \% \mathrm{MeOH}$ eluate $(534 \mathrm{mg}$ ) was applied on a Sephadex LH-20 column (GE Healthcare BioSciences AB, Uppsala, Sweden) and eluted with $\mathrm{CHCl}_{3}-\mathrm{MeOH}$ (1:1) to obtain crude 1 $(143 \mathrm{mg})$. The active eluate was purified by preparative reversedphase HPLC using a CAPCELL PAK C18 MGII column $(5.0 \mu \mathrm{m}, 20$ i.d. $\times 150 \mathrm{~mm}$; Shiseido, Tokyo, Japan) with $60 \%$ aqueous $\mathrm{MeOH}$ containing $0.1 \%$ formic acid (flow rate, $10 \mathrm{ml} \mathrm{min}^{-1}$ ) to yield 1 $(2.9 \mathrm{mg}$, retention time (Rt), $27.2 \mathrm{~min})$, along with JBIR-59 (14.6 mg, Rt, $19.3 \mathrm{~min}$ ) and bisorbibutenolide ${ }^{4}(2.6 \mathrm{mg}$, Rt, $32.8 \mathrm{~min})$. Compound 1 was a yellow amorphous solid: $[\alpha]_{\mathrm{D}}^{22}-282^{\circ}(\mathrm{MeOH}$; $c$ 0.15); UV $\lambda_{\max } \mathrm{nm}(\log \varepsilon)$ in $\mathrm{MeOH}: 232$ (4.11), 267 (4.09), 307 (3.95) and 385 (4.05); HR-ESI-MS: $m / z=431.2086[\mathrm{M}+\mathrm{H}]^{+}$, calculated for $\mathrm{C}_{24} \mathrm{H}_{31} \mathrm{O}_{7} 431.2070$. The IR absorption $\left(v_{\max } 1656 \mathrm{~cm}^{-1}\right)$ of 1 indicated the presence of an unsaturated ketone function. The direct connectivity between each proton and carbon was established by the heteronuclear single-quantum coherence (HSQC) spectrum. The ${ }^{13} \mathrm{C}$ and ${ }^{1} \mathrm{H}$ NMR spectral data for $\mathbf{1}$ are listed in Table 1. A planar structure was established by analyses of the double quantum-filtered (DQF)-COSY spectrum together with the constant time $\mathrm{HMBC}^{5}$ spectrum as follows.

The DQF-COSY spectrum appeared as consecutive correlations from the terminal methyl protons $\mathrm{H}_{3}-20\left(\delta_{\mathrm{H}} 1.88\right)$ to an olefinic methine proton $\mathrm{H}-16\left(\delta_{\mathrm{H}} 6.43\right)$ through three olefinic protons. In the HMBC spectrum, ${ }^{1} \mathrm{H}-{ }^{13} \mathrm{C}$ long-range correlations from singlet methyl protons $\mathrm{H}_{3}-14\left(\delta_{\mathrm{H}} 1.59\right)$ to an oxygenated olefinic carbon C-6 $\left(\delta_{\mathrm{C}} 167.6\right)$, a quaternary olefinic carbon $\mathrm{C}-7\left(\delta_{\mathrm{C}} 110.7\right)$ and an $\alpha, \beta$-unsaturated ketone $\mathrm{C}-8\left(\delta_{\mathrm{C}} 192.2\right)$; from methyl protons $\mathrm{H}_{3}-13\left(\delta_{\mathrm{H}} 1.42\right)$ to an oxygenated quaternary carbon $\mathrm{C}-5 \mathrm{a}\left(\delta_{\mathrm{C}} 80.0\right)$, a methine carbon C-9a $\left(\delta_{\mathrm{C}} 55.1\right)$ and C-6; from a singlet methine proton $\mathrm{H}-9 \mathrm{a}\left(\delta_{\mathrm{H}} 3.63\right)$ to C$5 a, C-6, C-8$ and an olefinic carbon C-9 $\left(\delta_{\mathrm{C}} 101.6\right)$, established a 1,3,4trioxygenated dimethylcyclohexenone ring. In addition, the correlations from the olefinic proton $\mathrm{H}-16$ to $\mathrm{C}-9$ and an oxygenated olefinic

${ }^{1}$ Biomedicinal Information Research Center, Japan Biological Informatics Consortium, Koto-ku, Tokyo, Japan and ${ }^{2}$ Biomedicinal Information Research Center, National Institute of Advanced Industrial Science and Technology, Koto-ku, Tokyo, Japan

Correspondence: Dr K Shin-ya, Biomedicinal Information Research Center, National Institute of Advanced Industrial Science and Technology, 2-4-7 Aomi, Tokyo 135-0064, Japan. E-mail: k-shinya@aist.go.jp

or Dr M Takagi, Biomedicinal Information Research Center, Japan Biological Informatics Consortium, Koto-ku, Tokyo 135-0064, Japan.

E-mail: motoki-takagi@aist.go.jp

Received 12 July 2011; revised 20 September 2011; accepted 28 September 2011; published online 19 October 2011 


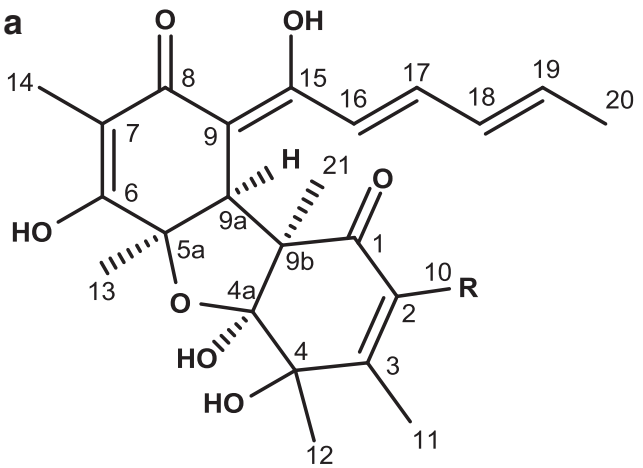

JBIR-124 (1): $\mathrm{R}=\mathrm{CH}_{3}$ JBIR-59: $\quad \mathrm{R}=\mathrm{H}$

b

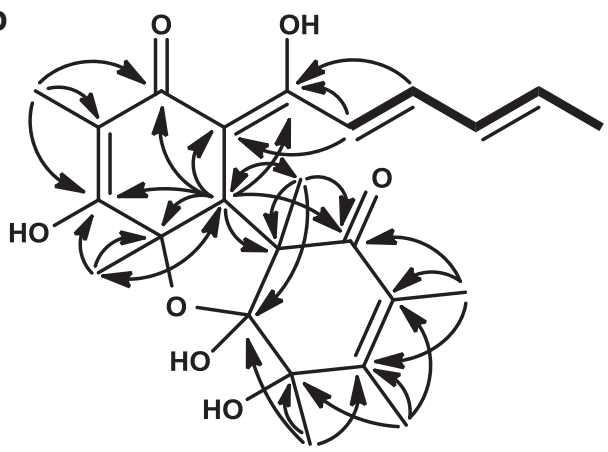

c

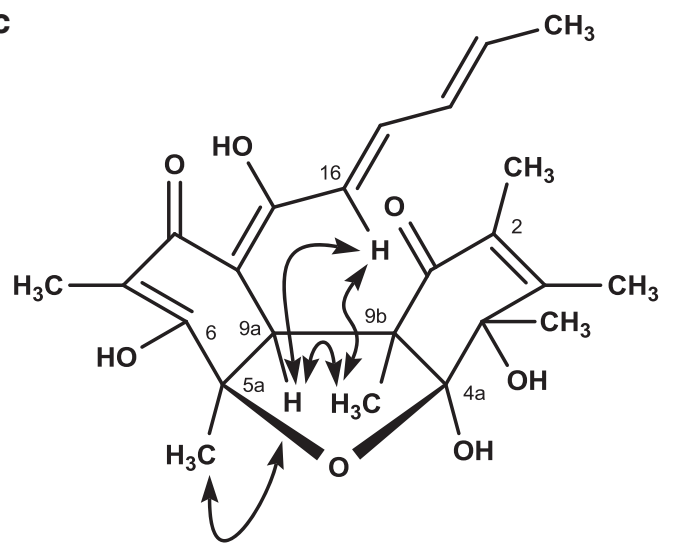

Figure 1 (a) Structure of JBIR-59 and 1. (b) Key correlations of double quantum-filtered-COSY (bold line) and HMBC (arrow, proton to carbon) of 1 . (c) NOESY correlations of $\mathbf{1}$ (arrow)

carbon $\mathrm{C}-15\left(\delta_{\mathrm{C}} 169.5\right)$, which long-range coupled in turn to the methine proton $\mathrm{H}-9 \mathrm{a}$, indicated that an olefinic chain motif (from C-16 to $\mathrm{C}-20$ ) was connected to $\mathrm{C}-15$ as shown in Figure $1 \mathrm{~b}$.

Furthermore, correlations from singlet methyl protons $\mathrm{H}_{3}-12\left(\delta_{\mathrm{H}}\right.$ $1.28)$ to an olefinic quaternary carbon $\mathrm{C}-3\left(\delta_{\mathrm{C}} 156.6\right)$, an oxygenated carbon C-4 $\left(\delta_{\mathrm{C}} 76.6\right)$ and a hemiketal carbon C-4a $\left(\delta_{\mathrm{C}} 106.1\right)$; from an allylic methyl signal $\mathrm{H}_{3}-11\left(\delta_{\mathrm{H}} 1.97\right)$ to 2 olefinic carbons $\mathrm{C}-2\left(\delta_{\mathrm{C}}\right.$ 131.0) and C-3, and C-4; from another singlet methyl proton $\mathrm{H}_{3}-10$ $\left(\delta_{\mathrm{H}} 1.55\right)$ to an $\alpha, \beta$-unsaturated ketone carbon $\mathrm{C}-1\left(\delta_{\mathrm{C}} 196.4\right), \mathrm{C}-2$ and C-3; from a remaining singlet methyl signal $\mathrm{H}_{3}-21\left(\delta_{\mathrm{H}} 1.26\right)$ to $\mathrm{C}-$ $1, \mathrm{C}-4 \mathrm{a}$ and a quaternary carbon $\mathrm{C}-9 \mathrm{~b}\left(\delta_{\mathrm{C}} 59.8\right)$ revealed a tetramethylhexenone ring. The connection between C-9a and C-9b was revealed by the correlations from $\mathrm{H}_{3}-21$ to C-9a. According to the 10 index of hydrogen deficiency deduced from the molecular formula of
Table $1{ }^{13} \mathrm{C}$ and ${ }^{1} \mathrm{H}$ NMR data for 1

\begin{tabular}{|c|c|c|}
\hline Position & $\delta_{C}$ & $\delta_{H}($ multiplicity, J in $\mathrm{Hz})$ \\
\hline 1 & 196.4 & \\
\hline 2 & 131.0 & \\
\hline 3 & 156.6 & \\
\hline 4 & 76.6 & \\
\hline $4 a$ & 106.1 & \\
\hline $5 a$ & 80.0 & \\
\hline 6 & 167.6 & \\
\hline 7 & 110.7 & \\
\hline 8 & 192.2 & \\
\hline 9 & 101.6 & \\
\hline $9 a$ & 55.1 & $3.63(\mathrm{~s})$ \\
\hline $9 b$ & 59.8 & \\
\hline 10 & 12.3 & $1.55(\mathrm{~s})$ \\
\hline 11 & 14.6 & $1.97(\mathrm{~s})$ \\
\hline 12 & 24.6 & $1.28(\mathrm{~s})$ \\
\hline 13 & 26.3 & $1.42(\mathrm{~s})$ \\
\hline 14 & 7.9 & $1.59(\mathrm{~s})$ \\
\hline 15 & 169.5 & \\
\hline 16 & 120.9 & $6.43(d, 15.0)$ \\
\hline 17 & 139.3 & $7.23(\mathrm{dd}, 11.4,15.0)$ \\
\hline 18 & 131.6 & $6.29(\mathrm{dd}, 11.4,15.0)$ \\
\hline 19 & 137.3 & $6.10(\mathrm{dq}, 6.6,15.0)$ \\
\hline 20 & 18.8 & $1.88(\mathrm{~d}, 6.6)$ \\
\hline 21 & 19.5 & $1.26(\mathrm{~s})$ \\
\hline
\end{tabular}

NMR spectra were taken on a Varian NMR System $600 \mathrm{NB} \mathrm{CL}$ in $\mathrm{CHCl}_{3}-d / \mathrm{MeOH}-d_{4}(1: 1)$ with the residual solvent peak as an internal standard $\left(\delta_{\mathrm{C}} 49.0, \delta_{\mathrm{H}} 3.35\right.$ p.p.m.).

1, the hemiketal carbon C-4a should connect to the other oxygenated carbon to construct a heterocyclic structure through an ether bond. The ${ }^{1} \mathrm{H}$ and ${ }^{13} \mathrm{C}$ NMR chemical shifts of 1 were well matched with those of JBIR-59, except for the C-2 moiety, and revealed the structure of $\mathbf{1}$ as shown in Figure 1a.

The configuration of the conjugated moiety was deduced as $16 E$, $18 E$ by the characteristic proton-proton coupling constants $\left({ }^{3} J_{16 \mathrm{H}-17 \mathrm{H}}\right.$ $=15.0 \mathrm{~Hz}$ and $\left.{ }^{3} J_{18 \mathrm{H}-19 \mathrm{H}}=15.0 \mathrm{~Hz}\right)$, respectively. A $Z$ geometry for C-9 was elucidated by NOESY correlations between $\mathrm{H}-16 / \mathrm{H}-9 \mathrm{a}$ and $\mathrm{H}-16 / \mathrm{H}_{3}-21$. The NOESY correlations between $\mathrm{H}-9 \mathrm{a} / \mathrm{H}_{3}-13$ and $\mathrm{H}-9 \mathrm{a} /$ $\mathrm{H}_{3}-21$ indicated that the hydroxy group at $\mathrm{C}-4 \mathrm{a}$, the hydrogen atom $\mathrm{H}-9 \mathrm{a}$, and the two methyl groups $\mathrm{CH}_{3}-13$ and $\mathrm{CH}_{3}-21$ were oriented in the same direction on the furan ring, as shown in Figure 1c.

We evaluated the 1,1-diphenyl-2-picrylhydrazyl (DPPH) radical scavenging activity of 1 . A 384-well plate was used for the DPPH radical scavenging assay. ${ }^{6}$ Compound $\mathbf{1}$ and $\alpha$-tocopherol as a positive control were dissolved in dimethyl sulfoxide to form the stock solution (1 mM). We mixed $10 \mu \mathrm{l}$ of $400 \mu \mathrm{M}$ DPPH dissolved in EtOH, $2 \mu \mathrm{l}$ of sample solution and $8 \mu \mathrm{l}$ of phosphate-buffered saline buffer in a 384well microplate. After 30-min incubation at room temperature, the absorbance was measured at $540 \mathrm{~nm}$. Compound 1 demonstrated DPPH radical scavenging activity with an $\mathrm{IC}_{50}$ value of $30 \mu \mathrm{M}$, which was almost the same as that of $\alpha$-tocopherol $\left(\mathrm{IC}_{50}=9.0 \mu \mathrm{M}\right)$ and JBIR$59\left(\mathrm{IC}_{50}=25 \mu \mathrm{M}\right)$.

\section{CONFLICT OF INTEREST}

The authors declare no conflict of interest.

\section{ACKNOWLEDGEMENTS}

This work was supported by a grant from the New Energy and Industrial Technology Department Organization of Japan. 
1 Hammond, B., Kontos, A. \& Hess, M. L. Oxygen radicals in the adult respiratory distress syndrome, in myocardial ischemia and reperfusion injury, and in cerebral vascular damage. Can. J. Physiol. Pharmacol. 63, 173-187 (1985).

2 Finkel, T. Radical medicine: treating ageing to cure disease. Nat. Rev. Mol. Cell Biol. 6 , 971-976 (2005).

3 Ueda, J., Hashimoto, J., Inaba, S., Takagi, M. \& Shin-ya, K. JBIR-59, a new sorbicillinoid, from a marine-derived fungus Penicillium citrinum SpI080624G1f01. J. Antibiot. 63, 203-205 (2010).
4 Abe, N., Murata, T. \& Hirota, A. Novel oxidized sorbicillin dimers with 1,1-diphenyl-2picrylhydrazyl-radical scavenging activity from a fungus. Biosci. Biotechnol. Biochem. 62, 2120-2126 (1998).

5 Furihata, K. \& Seto, H. Constant time HMBC (CT-HMBC), a new HMBC technique useful for improving separation of cross peaks. Tetrahedron Lett. 39, 7337-7340 (1998).

6 Izumikawa, M., Nagai, A., Doi, T., Takagi, M. \& Shin-ya, K. JBIR-12, a novel antioxidative agent from Penicillium sp. NBRC 103941. J. Antibiot. 62, 177-180 (2009) 